\title{
NILAI-NILAI PENDIDIKAN KARAKTER “MAJA LABO DAHU" DALAM PEDAGOGI
}

\author{
Tasrif \\ Universitas Negeri Yogyakarta Indonesia \\ E-mail: tasrifaziz@gmail.com
}

\begin{abstract}
Era globalisasi telah mengubah tatanan kehidupan sosial dan budaya masyarakat lokal. Semula kehidupan masyarakat terikat kuat pada nilai-nilai dan kearifan lokal yang hidup dalam masyarakat. Nilai-nilai tersebut menjadi pedoman hidup. Maja Labo Dahu adalah falsafah budaya Bima Nusa Tenggara Barat yang mengajarkan tentang rasa takut pada Tuhan, dan rasa malu pada sesama manusia. Tujuan penelitian ini yaitu untuk mendeskripsikan konsep pendidikan karakter maja labo dahu dalam kebudayaan Bima. Penelitian ini menggunakan metode deskriptif kualitatif dengan pendekatan analisis konten. Sumber data penelitian yaitu Maja Labo Dahu yang merupakan budaya lokal masyarakat Bima. Dari analisis konten terhadap falsafat budaya tersebut diperoleh hasil bahwa nilai-nilai yang ada pada Maja Labo Dahu mengandung pendidikan karakter bagi masyarakat. Perlu ada suatu konsep yang komperehensif dalam pembelajaran tentang filosofi Maja Labo Dahu ini. Nilainilai yang terkandung di dalamnya yaitu ketaatan dan ketundukan kepada Tuhan serta rasa malu melakukan tindakan amoral. Maja Labo Dahu harus diwujudkan sebagai shcool culture, family culture, dan social culture. Trias pendidikan tersebut sebagai tempat konservasi kearifan lokal Maja Labo Dahu.
\end{abstract}

Kata Kunci: pendidikan karakter, maja labo dahu, pedagogi

\section{CHARACTER EDUCATION VALUES IN "MAJA LABO DAHU" IN PEDAGOGY}

\begin{abstract}
The era of globalization had changed the social and cultural life of local communities. Initially, people's lives were strongly tied to local values and wisdoms that lived in the community. These values had become guidliness of life. Maja Labo Dahu is the philosophy of the Bima culture, West Nusa Tenggara which teaches fear of God and shame of fellow humans. The purpose of this study was to describe the concept of character education for Maja Labo Dahu of Bima culture. This research used a qualitative descriptive method with content analysis approach. The data source is Maja Labu Dahu which is the local culture of the Bima community. From the content analysis of the culture philosophy, the results show that the values in Maja Labo Dahu contain character education for the community. There needs to be a comprehensive concept in learning about the philosophy of Maja Labo Dahu. The values contained in it are obedience and submission to God and shame to commit immoral acts. Maja Labo Dahu must be manifested as shcool culture, family culture, and socio-culture. The educational triad is a place for the conservation of local wisdom of Maja Labo Dahu.
\end{abstract}

Keywords: character education, maja labo dahu, pedagogy

\section{PENDAHULUAN}

Pendidikan karakter sangat krusial dan menjadi kebutuhan mendasar sebuah bangsa (Arnott \& Ozga, 2010). Akhir-akhir ini tema pendidikan karakter semakin banyak diperbincangkan di tengah-tengah makin rusaknya perilaku siswa. Selain pendidikan karakter secara universal, pendidikan karakter berbasis pada kearifan lokal juga makin intens diformulasi (Chusorn, et al., 2014; Vitasura, 2016).
Para pendidik, terutama pada Pendidikan Anak Usia Dini, telah lama memperhatikan pendidikan karakter, moralitas dan nilai (Kohlberg, 1966; Kohn, 1997). Mereka berharap bahwa pendidikan karakter ditanamkan sejak usia dini. Karakter yang dimaksud adalah kepribadian yang melekat pada diri seseorang. Prinsip utama dari karakter adalah rasa hormat (respect), kebenaran (truth), adil (fair), dan bertanggung jawab (responsibilty) (Skaggs \& Bodenhorn, 
2006). Sementara itu, pembangunan karakter merupakan bagian penting dari kinerja pendidikan. Misi semua pendidikan adalah pendidikan karakter. Oleh sebab itu, pendidikan dianggap sebagai pusat keunggulan dalam mempersiapkan karakter unggul manusia.

Berbagai penelitian pendidikan karakter di kalangan remaja dan siswa mengungkapkan makin tingginya krisis pendidikan karakter di kalangan mereka. Hal ini karena masalah pendidikan di Indonesia sangatlah kompleks. Banyak aspek dalam pendidikan yang perlu diselesaikan dengan cepat dan tepat. Nilai-nilai karakter mulia, seperti kejujuran, kesantunan, kebersamaan, dan religius, secara gradual telah terkikis oleh kuatnya budaya asing yang cenderung hedonistik, materialistik, dan individualistik (Sujatmiko, 2019). Akhir-akhir ini nilai-nilai karakter tersebut tidak lagi dipandang penting bahkan dianggap bertentangan dengan tujuan yang ingin diperoleh. Begitu juga sebagai fakta sosial, dekadensi moral telah 'membatin' dalam kehidupan sosial masyarakat. Indikatornya yaitu makin maraknya drug abuse, perkelahian atau tawuran antarpelajar, kecurangan ujian, dan perilaku tidak terpuji lainnya. Begitu juga dalam demokrasi, terlihat makin tingginya indeks kejahatan seperti money politics, korupsi, dan penyalahgunaan jabatan (Kazali, et al., 2020).

Melihat fakta-fakta sosial tersebut, pengembangan manusia sebagaimana yang diamanatkan dalam konstitusi dan undang-undang tentang sistem pendididkan nasional menunjuk pada pembentukan karakter peserta didik sehingga mampu bersaing, beretika, bermoral, sopan santun, menghargai nilai-nilai kemanusiaan, dan mampu berinteraksi dengan masyarakat (Barus, 2015).
Nilai-nilai karakter identik dengan budi pekerti yang merupakan kesatuan jiwa yang hidup membatin dalam diri manusia. Melihat hal tersebut, banyak kalangan yang menilai bahwa Indonesia menghadapi moral hazard yang membutuhkan penanganan secara presisi melalui pendekatan pendidikan karakter di semua tingkatan pendidikan (Mulyasa, 2007).

Pada masyarakat Bima, pergaualan dan relasi sosial telah bergeser dari masyarakat yang menekankan kohesi sosial perlahan menjadi antisosial. Konflik sosial, bunuh diri remaja, perkelahian, perampokan, dan pencurian merupakan masalah sosial. Hal itu disebabkan salah satunya oleh pengaruh nilai-nilai asing yang menggeser filfasat hidup Maja Labo Dahu sebagai kekuatan nilai-nilai kearifan lokal (local wisdom) tanpa melalui proses filterisasi (Jurdi, 2008). Kearifan lokal adalah kekayaan budaya berupa nilai, bahasa, adat istiadat, pengetahuan termasuk mistik yang bertumbuh dan berkembang dalam sebuah komunitas masyarakat yang dikenal, dipercaya, dan diakui sebagai pranata hidup yang mampu memperteguh kohesi dan sistem sosial masyarakat lokal (Abdullah, 2010).

Maja Labu Dahu merupakan saripati kearifan lokal yang bertumbuh dan berkembang bersama masyarakat dalam kebudayaan Bima dalam kurun waktu yang cukup lama. Di masa lalu maja labo dahu berawal saat kejayaan kesultanan Bima Nusa Tenggara Barat. Kesultanan Bima merupakan kesultanan di Indonesia bagian Timur yang hidup sekitar tahun 1621 Masehi, terkenal karena ketaatan dan ketundukannya pada ajaran Islam. Selain itu, Bima juga diakui sebagai masyarakat yang taat pada sistem budaya atau adatnya, dan sistem budaya yang mereka pegang teguh harus sesuai dengan norma agama. Rimpu baik sebagai tradisi maupun titah agama 
menjadi indentitas masyarakat Bima yang telah pudar meski telah berwujud dalam kebudayaan modern. Rimpu adalah penutup kepala dari sarung khas Bima. Rimpu bermakna pakaian wanita muslimah untuk menutup aurat. Dan beberapa identitas lokal Bima yang sudah hilang dalam kehidupan sosial masyarakat (Mutawalli, 2013).

Dalam catatan Bo' Sangaji Kai sebuah buku babon penting Kerajaan Bima dijelaskan bahwa Kerajaan Bima merupakan sebuah kerajaan yang sangat teratur tata pemerintahannya yang memiliki relasi yang sangat luas dengan pemerintahan lainnya. Kerajaan Bima di masanya mengembangkan suatu pola dan sistem politik dan budaya yang canggih karena kemakmuran yang dihasilkannya melalui perniagaan. Secara geopolitik, Bima terletak di tengah jalur maritim yang melintasi Kepulauan Indonesia, sehingga menjadi tempat persinggahan penting dalam jaringan perdagangan dari Malaka ke Maluku. Sejumlah peninggalan purbakala dan prasasti serta beberapa kutipan dari teks Jawa Kuno seperti Nagarakertagama dan Paraton membuktikan bahwa pelabuhan Bima telah disinggahi sekitar abad ke-10. Maja Labo Dahu adalah tradisi verbal masyarakat Bima (Chambert-Loir \& Salahuddin, 1999).

Begitu pentingnya nilai-nilai karakter dalam Maja Labo Dahu bagi kaum muslim di Bima khususnya dan bagi masyarakat muslim Indonesia umumnya sehingga nilai-nilai yang ada dalam falsafah local ini perlu dipertahankan dan dikembangkan. Penelitian ini mengkaji nilai-nilai karakter Maja Labo Dahu dalam perspektif pedagogis, yakni dengan menganalisis pentingnya nilai-nilai karakter dalam falsafah tersebut untuk dijadikan salah satu sumber kearifan lokal dalam rangka penguatan pendidikan karakter.

\section{METODE}

Jenis penelitian ini adalah penelitian deskriptif dengan menggunakan analisis isi (content anaysis). Krippendorff (2004) mengartikan bahwa analisis isi merupakan metode penelitian yang digunakan untuk membuat kesimpulan yang dapat direplikasi dan divalidasi dari teks dalam konteks penggunaannya. Analisis isi digunakan untuk mendeskripsikan isi teks komunikasi yang nyata. Manifestasi dalam analisis isi mengacu pada yang terlihat dan teks komunikasi eksplisit (Drisco \& Maschi, 2016). Objek penelitian ini yaitu kearifan lokal Maja Labo Dahu yang ada dalam kebudayaan Bima dan tertuang dalam beberapa tulisan, seperti buku yang ditulis Chambert-Loir \& Salahuddin (1999) dan tesis yang ditulis Mutawali (2013). Data-data yang diteliti terjaga keaslian dan kualitasnya. Analisis isi menjadi dasar dalam pembahasan penelitian yang dilakukan secara deskriptif kualitatif. Analisis isi ini dilakukan dengan tahapan pengadaan data, reducing data, inferencing data, dan analysing data.

\section{HASIL DAN PEMBAHASAN}

Dalam sejarah kerajaan di Nusantara, Bima tercatat sebagai pelabuhan persinggahan penting bagi lalu lintas niaga Nusantara. Tome Pires (1540) (ChambertLoir \& Salahuddin, 1999, p. xiii) mengatakan bahwa Jawa dan Bima telah menjadi transit pemburu rempah-rempah dari Malaka menuju Maluku. Sejumlah kapal dagang berlayar dari Malaka ke Maluku pada abad ke 15, memilih Bima sebagai tempat transit strategis dan telah menjadi pusat perdagangan yang berarti. Bila dibandingkan daerah-daerah lain di Indonesia, misalnya Jawa dan Sumatera, Bima termasuk terlambat menerima pengaruh Islam. Islam sudah masuk ke Sumatera sekitar abad ke 
7 M, sedangkan Bima menurut Rahman (2009) baru mendapat pengaruh Islam sekitar abad ke 17 (1618 M). Kerajaan Bima merupakan salah satu dari kerajaan yang pernah ada di Pulau Sumbawa. Beberapa kerajaan yang ada di pulai ini yaitu Kerajaan Dompu, Kerajaan Sanggar, Kerajaan Tambora, Kerajaan Pekat, Kerajaan Sumbawa, dan Kerajaan Bima. Kerajaan Bima adalah kerajaan yang bercorak Islam pada tahun 1621 M (Chambert-Loir \& Salahuddin, 1999). Di masa kejayaannya, Kerajaan Bima memiliki kekayaan hasil bumi yang melimpah. Hingga kini Bima terkenal dengan kuda dan susu kuda liar. Di samping itu, Bima menjadi bagian dari dunia kebudayaan Melayu dan merupakan bagian dari ummat Islam.

Kelebihan sistem budaya Mbojo diakui oleh banyak pakar antara lain MR. Van Volenhoven, seorang ahli hukum Adat dari Belanda, bahwa sistem atau struktur pengaturan pelaksanaan adat Kesultanan Bima adalah sangat sistematis dan sangat kuat. Pola yang dipakai adalah pola pengaturan Bugis Makassar, tetapi dalam bentuk yang agak berlainan dan lebih demokratis dan justru di situlah letak kekuatannya. Karena itu, A. Couver seorang asisten Residen Belanda untuk wilayah Sumbawa/ Sumba menyatakan bahwa untuk menguasai Kesultanan Bima hanyalah dengan melemahkan adatnya (Chambert-Loir \& Salahuddin, 1999).

Seruan Allah dan anjuran Rasul untuk melaksanakan adat (kebiasaan) yang baik dipatuhi oleh masyarakat masa lalu. Agar perintah Allah dan Rasul itu tetap diikuti dan dipatuhi oleh masyarakat, Sultan dan ulama membuat satu gagasan yang dijadikan falsafah hidup dan diberi nama Maja Labo Dahu. Maja artinya malu dan dahu artinya takut, sementara labo adalah konjungsi yang bermakna dan. Jadi
Maja Labo Dahu adalah frase yang bermakna siapa saja yang melanggar perintah Tuhan dan Rasul-Nya, dia harus malu dan takut pada Tuhan, malu pada manusia lainnya, dan juga malu pada dirinya sendiri. Dan apabila melanggar falsafah Maja Labo Dahu, berarti dia melanggar perintah agama dan adatnya. Hal inilah yang menyebabkan masyarakat Bima selalu taat serta bersungguh-sungguh melaksanakan perintah agama dan adatnya (Mulyadin \& Jaedun, 2019; Umar, Hendra, \& Yussof, 2019; Komariah, 2018).

Dari kacamata agama, Maja Labo Dahu merupakan sifat religius yang harus dimiliki oleh orang yang beriman dan bertakwa, sebab orang yang beriman harus memiliki sifat dahu (takut) kepada Allah dan Rasul. Ukuran taho (kebaikan) dan iha (kejahatan) pada ungkapan tersebut adalah berpedoman pada nilal-nilai luhur yang terkandung dalam iman dan takwa. Maka, melalui Maja Labo Dahu manusia akan berupaya untuk menegakkan amar ma'ruf nahi munkar sehingga manusia akan dapat berperan sebagai khalifatullah baik di muka bumi dan sebagai pengabdi Allah ('abdul$l a h)$. Kalau upaya tersebut dapat dilaksanakan, maka cita-cita menuju Sana Moridi Dunia Akhera (kebahagiaan di dunia dan akhirat) dan berlakunya sistem nilai budaya seperti yang terkandung dalam adat Mbojo dapat diwujudkan menjadi kenyataan, baik dalam wujud tingkah laku maupun kebudayaan fisik.

Pada dasarnya fungsi dan peranan Maja Labo Dahu adalah untuk menumbuhkan serta meningkatkan keimanan dan ketakwaan masyarakat, agar dalam melakukan tugasnya sebagai khalifah Allah selalu mendekatkan diri kepada-Nya melalui kegiatan 'ubudiyyah serta mu'amalah'. Dalam melakukan tugasnya, mereka selalu meme- 
gang teguh nilai-nilai luhur Maja Labo Dahu sebagai berikut.

1. Renta ba rera kapoda ade ro karani ba weki, yang artinya yang diikrarkan oleh lidah harus sesuai dengan suara hati nurani dan pula diamalkan.

2. Mbolo ra dampa atau mafaka ro dampa, yang benar menjunjung tinggi azas kekeluargaan dan musyawaran.

3. Karawi kaboju, artinya gotong-royong. Apa yang dihasilkan dalam musyawarah harus diprogramkan dan dilaksanakan oleh seluruh masyarakat secara gotong-royong.

4. Nggahi rawi pahu, yang berarti bahwa apa yang diikrarkan, dalam arti yang telah diprogramkan harus diwujudkan menjadi kenyataan.

5. Suu sawa'u sia sawale, yang artinya bagaimana pun beratnya tugas yang diemban, harus dijalankan dengan sabar dan tabah, pantang untuk lari dari tanggungjawab.

6. Tahompa ra nahu surapu dou labo dana, yang bermakna semua hasil pembangunan yang telah dicapai melalui perjuangan seluruh rakyat harus dinikmati secara adil sesuai besar kecilnya tanggung jawab.

7. Tahompa ra nahu sura dou ma rinpa. Nilai luhur ini ditujukan kepada kelompok yang memilki nilai lebih, baik dari segi harta maupun kekuasaan, agar selalu memikirkan kepentingan orang lain dan harus memiliki kepedulian yang tinggi (Mutawali, 2013).

Dari uraian di atas dapat disimpulkan bahwa fungsi dan peran Maja Labo Dahu yaitu meningkatkan kualitas jati diri serta sumber daya manusia secara utuh. Maja Labo Dahu merupakan adat Mbojo yang bernilai Islam sebagai fu'u mori ro woko yang telah melalui fase yang sangat panjang, mulai dari masa awal berdirinya kesultanan Bima sampai kini bahwa ungkapan maja labo dahu masih menjadi ungkapan yang bernilai pendidikan karakter dan budaya. Bahkan, ungkapan tersebut dijadikan sebagai ungkapan motto sekolah, lembaga pendidikan dan pemerintahan. Penyebab utama dari kejayaan Bima pada masa Kesultanan ialah karena masyarakat taat menjalankan perintah agamanya secara utuh (kaffah). Selain taat melaksanakan 'ubudiyyah, di bidang mu'amalah mereka tetap berpedoman pada nilai-nilai dan norma agamanya.

Seiring dengan dinamika peradaban modern yang memasuki era kesejagatan ditambah dengan era reformasi di Indonesia berimbas pada dinamika perubahan sosial baik kearah positif termasuk pada masyarakat Bima. Permasalahan sosial yang disarankan adalah kecenderungan munculnya perilaku masyarakat yang menyimpang dari koridor agama, etika, moral, dan hukum. Dengan adanya kebijakan pemerintah pusat tentang otonomi daerah, maka Bima sebagai sebuah komunitas yang mayoritas penduduknya beragama Islam menginginkan agar Bima menerapkan syariat Islam mengikuti daerah-daeran lain yang memiliki semangat yang sama. Semangat tersebut bermula dari kebijakan pemerintah daerah yang menginginkan agar kehidupan di Bima berlandaskan pada nilai-nilai yang bersifat Islami. Semangat memerintah tersebut diikuti pula oleh beberapa program daerah program seperti membumikan Alquran. Hasil yang diharapkan dari program membumikan Alquran tersebut yatiu terbentuknya atau bangkitnya kembali karakter komunikasi muslim yang syarat dengan nilai-nilai Islam yang ditandai dengan terbangunnya tiga dimensi kesinambungan dan harmonisnya hubungan antara manusia dan 
Tuhannya, dengan sesamanya serta dengan alam lingkungan.

Beberapa indikator terimplementasinya nilai-nilai seperti di atas di antaranya yaitu: (1) terbangunnya etika dasar menghadapi perbedaan yang merujuk pada sikap; merespons perbedaan sebagai sunnatullah dan dinikmati sebagai keindahan, memandang setiap komunitas sebagai sesuatu yang sudah final (meskipun dalam kenisbian) dan memahami setiap ekspresi yang ditawarkan oleh setiap komunitas baik dalam bentuk cara maupun dalam bentuk olah kata diterima sebagai saling melengkapi; dan (2) terimplementasinya etika sosial dalam dinamika kehidupan kolektif komunitas Bima yang merepresentasikan sikap sebagai penyebar salam perdamaian, persaudaraan dan persahabatan, penyambung silaturrahmi, penyantun yang lemah, pengucap yang sejuk dan pengasah kecerdasan spiritual. Dengan terpenuhinya minimal dua indikator tersebut diharapkan dapat terwujud karakter insan yang rahmatan lil 'alamin dan juga program dari Pemerintah Kabupaten Bima, yaitu antara lain dengan ditandatanganinya Piagam Jumat Khusyu' (Perda Nomor 14 Tahun 2013), Bima Ikhlas, Magrib Mengaji dan masih banyak lagi program yang berlandaskan pada nilai-nilai Islam. Meskipun demikian, masih terlihat bahwa penerapan syariat Islam tersebut masih bersifat simbolik.

Maja Labo Dahu adalah budaya verbal yang mengandung kearifan lokal (local wisdom) masyarakat Bima. Kearifan ini muncul sejak jaman kesultanan Bima (1621 M). Maja Labo Dahu mengadung dua dimensi kompetensi yaitu kompetensi sosial (maja) dan kompetensi religius (dahu). Sebagai kearifan lokal, Maja Labo Dahu menyiratkan beberapa konsep, yaitu: (1) kearifan lokal adalah sebuah pengalaman panjang, yang dijadikan sebagai petunjuk perilaku seseorang; (2) kearifan lokal tidak lepas dari lingkungan pemiliknya; dan (3) kearifan lokal itu bersifat dinamis, lentur, terbuka, dan senantiasa menyesuaikan dengan perkembangan zaman. Konsep demikian juga sekaligus memberikan gambaran bahwa kearifan lokal selalu terkait dengan kehidupan manusia yang hidup di lingkungan alam dan sosialnya. Kearifan lokal muncul sebagai penjaga atau filter nilai-nilai global yang melanda kehidupan manusia (Wagiran, 2012). Nilai-nilai kearifan lokal tersebut menjadikan masyarakat mampu beradaptasi dengan alam dan lingkungannya sehingga mampu membentuk karakter masyarakat.

Dahu atau takut berbeda dengan phobia sebagai makna psikologi. Dalam psikologi phobia adalah takut yang berlebihan terhadap sesuatu yang tidak membahayakan. Misalnya acrofobia adalah ketakukan yang berlebihan pada ketinggian. Semenatara takut dalam arti dahu adalah rasa takut untuk tidak melakukan perbuaan maksiat atau melawan perintah Tuhan. Menurut Imam Al-Ghazali takut atau khauf adalah suatu perasaan takut yang mencegah anggota badan dari perbuatan maksiat dan diikat dengan ketaatan (Zulfikar, 2019). Orang mukmin adalah orang yang takut kepada Allah beserta seluruh anggota badannya. Dahu adalah rasa takut yang bernilai ibadah yakni rasa takut yang ditujukan hanya kepada Allah, di mana dengan rasa takut tersebut menjadikannya tidak berani berbuat maksiat dan melanggar aturan-aturan Allah dan berusaha untuk tidak melakukan hal yang mendatangkan murkan-Nya. Rasa takut yang seperti ini bila ditujukan kepada selain manusia maka termasuk musyrik (Al-Ramli, 2012). Dahu dalam berbagai bentuk derivasinya dapat ditemukan di dalam Al-Qu'ran. Kata dahu 
tersebar pada 40 ayat dalam 24 surat (AlAsfahani, 2004; Zulfikar, 2019). Dari banyak penyebutan kata dahu atau takut ini seluruhnya mengacu kepada makna takut kepada Allah (khasyyatullah) kecuali ayat 11 ayat yang bermakna takut secara naluriah atau formal yaitu yaitu terdapat pada QS. Taha [20]: 44, 77, 94, QS. al-Israe [17]: 31, 100, QS. Ali „Imran [3]: 173, QS. Luqman [31]: 33, QS. al-Nazie'at [79]: 45, QS. alNisae [4]: 25, QS. al-Taubah [9]: 24, dan QS. al-Kahfi [18]: 80.

Kata Maja Labo Dahu secara kultural mendorong dou mbojo dalam hal ini masyarakat Bima untuk melaksanakan ibadah dengan senantia menjalankan perintah Allah dan menjauhi segala larangan Allah. Makna ini menjelaskan perasaan heroisme untuk tidak takut pada medan perang atau pertempuran karena secara hakikat yang paling ditakuti hanya kepada Allah. Penerapan konsep penyampaian karakter anak melalui budaya Majo Labo Dahu belum sepenuhnya dipahami dan dipraktikkan oleh sebagian besar masyarakat Bima. Konsep pembentukan karakter anak melalui budaya masyarakat Maja Labo Dahu Bima meliputi tiga tahapan utama, yaitu: (1) seorang anak sejak usia dini harus dikenalkan dengan budaya Maja Labo Dahu melalui keteladanan orang tua, guru, dan tokoh masyarakat; (2) seorang anak harus memahami nilai-nilai budaya Maja Labo Dahu melalui pembelajaran akhlak yang dilandasi oleh keterpaduan pentingnya ajaran agama dan budaya; dan (3) seorang anak berkewajiban menerapkan perilaku budaya masyarakat Maja Labo Dahu melalui praktik sikap yang didasarkan pada proses aktualisasi ajaran agama di lingkungan keluarga, sekolah, dan masyarakat. Pengenalan maja Labo labo Dahu kultur cenderung mengutamakan pesan moral yang mengadopsi nilai-nilai agama, terutama ajaran Islam seperti menjaga perilaku dalam kehidupan sehari-hari, dan menghormati sesama manusia.

Selain dalam aspek ibadah, penerapan Maja Labo Dahu sering disebut orang tua pada anak sebagai bentuk nasehat saat akan merantau menuntut ilmu. Pesan dan nasehat orang tua sering diungkapkan seraca imperatif. Pesan bermakna anak akan sukses bila seorang anak harus tetap taat beribadah tidak boleh jauh dari Tuhan dan harus malu kalau tidak sukses dan melakukan tindakan amoral di tanah rantauan.

Untuk menanamkan nilai-nilai karakter pada peserta didik dan juga pada bangsa baik nilai yang lahir dari budaya universal atau local wisdom, pendidikan keluarga berkontribusi besar terhadap internalisasi nilai. Keluarga, orang tua, dan pendidikan prasekolah berada di garis depan dalam membimbing anak-anak untuk mengetahui, peduli dan bertindak berdasarkan nilai-nilai etika dalam pengalaman kehidupan sehari-hari. Sebagai contoh, hasil-hasil penelitian (Lockwood, 1997; White \& Warfa, 2011) tentang pendidikan karakter di Taiwan yang proses panjang mendidik anak-anak untuk mengembangkan karakter yang baiknya dapat dilacak dari tradisi nilai-nilai Konfusianisme. Pendidikan karakter Taiwan merupakan integrasi atau percampuran kegiatan pembelajaran pendidikan moral atau karakter ke dalam pendidikan keluarga agar anakanak memperoleh, mengatur, dan mendemonstrasikan dan mengomunikasikan informasi (Berkowitz \& Melinda, 2004; Berkowitz \&Bier, 2005; Althof \& Berkowitz, 2006). Di Indonesia sudah lebih dari satu dasa warsa upaya pengintegrasian pendidikan karakter melalui pembelajaran di kelas (Marzuki, 2021).

Pemahaman yang memadai tentang nilai budaya dalam diri seorang anak dapat 
mendorong semangat hidup sekaligus menjadi identitas budaya yang harus dijaga dan dilaksanakan dalam kehidupan sosial anak (Smith, et al., 2019). Dilihat dari perspektif pendidikan Islam, budaya Maja Labo Dahu adalah muatan pendidikan akhlak. Alhasil, dalam memberikan pemahaman budaya kepada seorang anak dapat dilakukan melalui pendekatan pembelajaran berbasis penguatan akhlak sejak dini pada individu. Untuk itu anak diajarkan dengan sikap jujur, memotivasi anak dalam menyelesaikan tugas, membimbing anak berpandangan toleransi terhadap orang lain, menjelaskan tata cara menghormati orang tua, dan guru,

Ülger, et al., (2014, p. 443) merekomendasikan bahwa guru yang melaksanakan program pengajaran harus kompeten baik di bidangnya maupun dalam pendidikan karakter untuk mendidik generasi yang berkualitas. Model guru masa lalu banyak terlibat dalam mentransfer ilmu, diganti dengan model guru yang berpusat pada siswa dan pembelajaran serta sadar akan semua siswa di kelas dan terlibat dalam mempersiapkan pengalaman belajar yang cocok untuk pengembangan dan perbedaan individu semua siswa. Maja Labo Dahu merupakan konsep hidup yang lahir dari konstruksi sosial dan budaya masyarakat Bima. Nilai-niai karakter yang terkandung dalam budaya tersebut dianggap sebagai bagian dari unsur psiko-sosial yang terkait dengan lingkungan sekitar. Hal ini senada dengan pendapat Koesoema (2007, p. 79) yang mengatakan bahwa di dalam karakter terkandung unsur psychosocial yang lahir dari lingkungan budaya sekitarnya. Karakter juga dianggap sebagai elemen perilaku yang menekankan pada somatopsikis yang dimiliki oleh manusia.

Integrasi pendidikan karakter di sekolah dapat dilakukan dalam berbagai mata pelajaran sebagai implementasi gerakan pendidikan karakter di Indonesia. Berbagai penelitian relevan misalanya di Taiwan bahwa premis pendidikan karakter di mulai dari pendidikan prasekolah di mana ada enam bidang bagi guru prasekolah untuk menumbuhkan praktik pendidikan karakter bagi anak-anak, termasuk bahasa, kognisi, sosial, emosional, kesehatan fisik, dan estetika. Dengan prevalensi kepercayaan orang tua pada hasil belajar anak dianggap lebih penting daripada mereka penanaman pendidikan karakter, orang tua mengerahkan segala upaya untuk mendorong anak-anak mempelajari semua jenis kurikulum sekolah bahkan setelah jam sekolah. Dengan penekanan penelitian pada pentingnya keterkaitan orang tua-anak (Cillessen \& Mayeus, 2004; Elicker, et al., 1992; LaFontana \& Cillessen, 2001; Parker, et al., 1995).

Pengembangan karakter bangsa dilakukan melalui perkembangan karakter individu seseorang. Akan tetapi sebagai makhluk sosial dan budaya, maka perkembangan karakter individu dapat dilakukan dalam lingkungan sosial dan budaya sesorang. Artinya, perkembangan budaya dan karakter tidak dapat dilepaskan dari konteks budaya. Salah satu usaha yang dapat dilakukan oleh masyarakat sebagai upaya menghadapi dampak buruk globalisasi dengan tetap berpedoman pada nilainilai kearifan lokal sebagai suatu kekuatan. Kearifan lokal dapat berfungsi menjadi penyaring bagi nilainilai yang berasal dari luar yang kurang sesuai dengan kultur budaya bangsa (Kurnia, 2018, p. 52). Kearifan lokal merupakan hasil dari pengalaman masyarakat dalam lingkup wilayah tertentu. Nilai-nilai tersebut akan melekat sangat kuat pada masyarakat.

Terdapat beberapa nilai dalam budaya verbal Maja Labo Dahu seperti 
ketaatan religius, beribadah, berbuat baik, amoral, cinta lingkungan, kerja keras, baik dan rendah hati dan etos kerja. Nilai-nilai pilar karakter tersebut, diajarkan secara sistematis dalam model pendidikan holistik atau komprehensif dengan menggunakan metode knowing the good, feeling the good, dan acting the good sebagaimana disebutkan Thomas Lickona (1991). Menurut Zuchdi, et al. (2010) bahwa dari segi metode, pendekatan komprehensif meliputi inkulkasi (inculcation), keteladanan (modeling), fasilitasi (facilitation) dan pengembangan keterampilan (skill building). Inkulkasi nilai memiliki ciri-ciri seperti: (1) mengomunikasikan kepercayaan disertai alasan yang mendasarinya; (2) memperlakukan orang lain secara adil; (3) menghargai pandangan orang lain; (4) mengemukakan keraguan atau perasaan tidak percaya disertai dengan alasan dan dengan rasa hormat; (5) tidak sepenuhnya mengontrol lingkungan untuk meningkatkan kemungkinan penyampaian nilai-nilai yang dikehendaki; (6) menciptakan pengalaman sosial dan emosional mengenai nilai-nilai yang dikendendaki, tidak secara ekstrem; (7) membuat aturan, memberikan penghargaan, dan memberikan konsekuensi disertasi alasan; dan (8) tetap membuka komunikasi dengan pihak yang tidak setuju dan memberikan kebebasan bagi adanya perilaku yang berbeda-beda, dan apabila sampai pada tingkat yang tidak dapat diterima, maka diarahkan untuk memberikan kemungkinan berubah. Pendidikan karakter yang diintegrasikan dalam pembelajaran bebrgai bidang studi dapat memberikan pengalaman yang bermakna bagi muridmurid karena mereka memahami, menginternalisasi, dan mengaktualisasikannya melalui proses pembelajaran. Dengan demikian, nilai-nilai tersebut dapat terserap secara alami melalui kultur sekolah, sehingga pendidikan karakter akan lebih efektif (Lickona, 1991; Kirschenbaum, 1995; Zuchdi, 2009).

Kompetensi pendidikan karakter guru sangat penting dalam pencapaian tujuan pendidikan disamping pengetahuan lapangan, pengetahuan umum dan pengetahuan pedagogik (Ülgera, et al., 2014). Guru memiliki tanggung jawab terbesar dalam menginternalisasi karakter positif siswa. Peran guru dalam pendidikan karakter yaitu guru berperilaku dengan kasih sayang dan hormat kepada siswa, memberikan teladan yang baik dan mendukung perilaku sosial positif, mengajarakan perilaku hormat pada orang lain, bertanggung jawab terhadap teman teman sejawat, dan memberi disiplin dengan moral (Menurut (Lickona, 1991).

Maja Labo Dahu tidak saja mengandung kompetensi religius, tetapi ia juga memiliki dimensi kompetensi sosial. Hal ini senada dengan pandangan Leming (2008) bahwa pendidikan karakter akan meningkatkan kompetensi sosial seseorang. Sementara itu, seorang siswa harus memiliki komtensi sosial (Butts \& Cruzeiro, 2005). Kompetensi sosial adalah dasar untuk spektrum hasil perkembangan diri seseorang seperti harga diri, kesejahteraan sosial, kualitas persahabatan, penerimaan oleh teman sebaya, dan kompetensi kerja (Liang, et al., 2008). Kompetensi sosial itu sendiri merupakan hasil perkembangan yang berharga yang mewakili perkembangan positif, sosial, dan moral. Selain dari menguntungkan individu, kompetensi sosial menopang social harmony, integrasi sosial, serta penghindaran dan resolusi sosial konflik. Dengan demikian, kompetensi sosial menjadi satu kesatuan elemen penting sepanjang perkembangan seseorang (Engels et al., 2001). 


\section{SIMPULAN}

Maja Labo Dahu adalah tradisi verbal budaya Bima yang dipercaya dan dikenalkan hingga kini oleh masyarakat Bima. Maja labo dahu adalah pendidikan agama dan moral atau akhlak yang mengandung dunia dimensia yaitu dimensi sosial dan agama yang absolut. Nilai-nilai karakter Maja Labo Dahu terkait erat dengan nilainilai karakter yang dikembangkan melalui program pendidikan karakter bangsa oleh pemerintah Indonesia yang di antara nilainilai pokoknya yaitu religius, ketaatan, toleransi, dan saling mambantu antarsesama.

Fenomena eksistensi Maja Labo Dahu dapat dlihat dari segi komponennya, pendidikan karakter lebih menekankan tiga komponen karakter yang baik (components of good character) yaitu moral knowing atau pengetahuan tentang moral, moral feeling atau perasaan tentang moral, dan moral action atau perbuatan bermoral. Meski menjadi ikon budaya, motto, dan budaya verbal masyarakat, nampaknya nilai-nilai Maja Labo Dahu telah hilang baik sebagai moral knowing, moral feeling, maupun moral action.

\section{UCAPAN TERIMA KASIH}

Dengan terselesaikannya tulisan ini, penulis bersyukut kepada Allah Swt dan menyampaikan ucapan terima kasih yang setulus-tulusnya kepada semua pihak yang telah membantu proses penelitian hingga penulisan. Secara khusus penulis mengucapkan terima kasih kepada ketua dewan redaksi Jurnal Pendidikan Karakter yang telah menerima dan memuat artikel ini pada edisi sekarang ini.

\section{DAFTAR PUSTAKA}

Abdullah, I. (2010). Konstruksi dan reproduksi kebudayaan. Yogyakarta: Pustaka Pelajar.
Addullah, I., dkk. (Eds). (2008). Agama dan kearifan lokal dalam tantangan global. Yogyakarta: Pustaka Pelajar.

Al-Ashfahani, A. (2004). Mu'jam mufradat li alfazh al-Qur'an. Beirut: Dar al-Kutub al-'Alamiyah.

Al-Ramli, M. S. A. (2012). Khauf minallah. Jakarta: Al Kautsar.

Althof, W., \& Berkowitz, M. W. (2006). Moral education and character education: Their relationship and roles in citizenship education. Journal of moral education, 35(4), 495-518. DOI:10.1080/03057240601012204.

Arnott, M. \& Ozga, J. (2010). Education and nationalism: The discourse of education policy in Scotland. Discourse: Studies in the Cultural Politics of Education, 31(3), 335- 350. DOI: 10.1080/01596301003786951.

Barus, G. (2015). Manakar hasil pendidikan karakter terintegrasi di SMP. Cakrawala Pendidikan, 34(2), 222-233. DOI: https:// doi.org/10.21831/cp.v2i2.48 27.

Berkowitz, M. W. \& Melinda, C. B. (2004). Research-based character education. The Annals of the American Academy of Political and Social Science, 591(1), 7285. https://doi.org/10.1177/0002716203260082 .

Berkowitz, M.W. \& Bier, M.C. (2005). What works in character education: a researchdriven guide for educators. Washington DC: Univesity of MissouriSt Louis.

Butts, M.J., \& Cruzeiro, P.A. (2005). Student perceptions of factors leading to an effective transition from eighth to ninth grade. American Secondary Education, 34(1), 70-80. Retrieved from 
https://www.jstor.org/stable/4106456 4.

Chambert-Loir, H. \& Salahuddin, S. M. R. (1999). Bo' Sangaji Kai: Catatan Kerajaan Bima. Jakarta: Yayasan Obor Indonesia.

Chusorn, P., Ariratama, W., Chusorn, P. (2014). Strategy challenges the local wisdom appications sustainability in schools. Procedia-Social and Behavioral sciences 112 (626-634).

Cillessen, A. H.N. \& Mayeux, L. (2004). From censure to reinforcement: Developmental changes in the association between aggression and social status. Child Development, 75(1), 147163. DOI: $10.1111 /$ j.1467-8624.2004.00660.x

Drisco, J. \& Maschi, T. (2016). Content analysis. New York: Oxford University Press.

Elicker, J, Englund, M., \& Sroufe, L. (1992). Predicting peer competence and peer relationships in childhood from early parent-child relationships. In $\mathrm{R}$. Parke \& G. Ladd (Eds.). Family-peer relationships: Modes of linkage. Hillsdale, NJ: Erlbaum.

Engels, R.C.M.E., Finkenauer, C., Dekovic, M., \& Meeus, W. (2001). Parental attachment and adolescents' emotional adjustment: The associations with social skills and relevant competence. Journal of Counseling Psychology, 48(4), 428-439. DOI:10.1037/0022-0167.48.4.428 .

Jurdi, S. (2008). Islam masyarakat madani dan demokrasi di bima: Membangun demokrasi yang kultural berbasis religius. Yogyakarta: Center of Nation Building Studies.
Kazali, R., Rochmiatun, E., Adytyas, N.O. (2020). Pengaruh money politics terhadap pilihan masyarakat pada pilkades serentak di Kabupaten Muara Enim tahun 2017 (Studi kasus di Desa Teluk Limau Kecamatan Gelumbang). Ampera: A Research Journal on Politics and Islamic Civilization, 1(2), 136-144, DOI: https://doi.org/10.19109/ampera.v1i2.5557.

Kirschenbaum, H. (1995). 100 ways to enhance values and morality in schools and youth settings. Boston: Allyn and Bacon.

Koesoema, D. (2007). Pendidikan karakter strategi mendidik anak di zaman global. Jakarta: Gramedia Widiasarana Indonesia.

Kohlberg, L. (1966). Moral education in the schools: A developmental view. The School Review, 74(1), 1-30. DOI: http: //www.jstor.org/stable/1084286.

Kohn, A. (1997). How not to teach values: A critical look at character education. Phi Delta Kappan, 78, 428-439. Retrieved from https://eric.ed.gov/?id$=$ EJ539111.

Komariah, S. (2018). Model penguatan karakter masyarakat berbasis nilai kearifan lokal "Maja Labo Dahu" dalam perspektif budaya Bima. Jurnal Ilmiah Administrasi Negara, 15(2), 98-114. Retrieved from http://administrasistisip.ejournal.web.id/index.php/ad ministrasistisip/article/view/147.

Krippendorff, K. (2004). Content analysis: An introduction to its methodology. Thousand Oaks, CA: SAGE Publication.

Kurnia, I. (2018). Mengungkap Nilai-nilai Kearifan Lokal Kediri Sebagai Upaya Pelestarian Budaya Bangsa Indone- 
sia. Jurnal PGSD: Jurnal ilmiah Pendidikan Guru Sekolah Dasar, 11(1), 5163. DOI: https://doi.org/10.33369/pgsd.11.1.51-63.

LaFontana, K.M. \& Cillessen, A.H.N. (2001). The nature of children's stereotypes of popularity. Social Development, 7(3), 301-320. DOI:10.1111/1467-9507.00069.

Leming, J. (2008). Research and practice in moral and character education: Loosely Coupled Phenomena. In L. P. Nucci \& D. Narvaez (Eds.), Handbook of moral and character education (pp. 134-157). New York: Routledge.

Liang, B., Tracy, A., Kenny, M., \& Brogan, D. (2008). Gender differences in the relational health of youth participating in a social competency program. Journal of Community Psychology, 36(4), 499-514. DOI: https:// doi.org/10.1002/jcop.20246.

Lickona, T. (1991). Educating for character, how our schools can teach respect and responsibility. New York: Bantam Books.

Lockwood, A.T. (1997). Character education: Controversy and consensus. Controversial Issues in Education Series. Thousand Oaks, CA: Corwin Press, Inc. Retrieved from https://eric.ed.gov $/$ ?id=ED421749.

Marzuki. (2012). Pengintegrasian pendidikan karakter dalam pembelajaran di sekolah. Jurnal Pendidikan Karakter, 2(1), 33-44. DOI: https://doi.org/10.21831/jpk.v0i1.1450.

Mulyadin, M., \& Jaedun, A. (2019). Maja Labo Dahu slogan in character education. Jurnal Pendidikan Karakter, 9(2), 204-2015.
DOI: https://doi.org/10.21831/jpk.v 9i2.22311.

Mulyasa, E. (2007). Standar kompetensi dan sertifikasi guru. Bandung: Remaja Rosdakarya.

Mutawali, M. (2013). ISLAM DI BIMA Implementasi Hukum Islam Oleh Badan Hukum Syara Kesultanan Bima (19471960). Bima: Alam Tara Institut Mataram. Retrieved from https://thesiscommons.org/m9c6n/.

Parker, J.G., Rubin, K.H. Price, J.M., DeRosier, M.E. (1995). Peer relationships, child development, and adjustment: A developmental psychopathology perspective. Developmental Psychopathology: Risk, Disorder, and Adaptation, 2, 96-161. DOI: https://doi.org/10.1002/9780470939383.ch12.

Rahman, M.F. (2009). Perkembangan Islam masa kesultanan. Yogyakarta: Genta Press.

Skagg, G. \& Bodenhorn, N. (2006). Relationships between implementing character education, student behavior, and student achievement. Journal of Advanced Academics, 18(1), 82-114. DOI: https://doi.org/10.4219/jaa2006-345.

Smith, E. P., Witherspoon, D. P., Bhargava, S., \& Bermudez, J. M. (2019). Cultural values and behavior among African American and European American children. Journal of Child and Family Studies, 28(5), 1236-1249. https://doi.org/10.1007/s10826-019-01367-y.

Sujatmiko, I.N. (2019). Pengiatan pendidikan karakter di SD. Jurnal Pendidikan, Vol. 4, No. 8. Thn 2019. Hal $1113-1119$. 
Ülger, M., Yiğittir, S., \& Ercan, O. (2014). Secondary school teachers' beliefs on character education competency. Procedia - Social and Behavioral Sciences, 131(2014), 442-449. DOI: 10.1016/j.sbspro.2014.04.145.

Umar, U., Hendra, H., \& Yussof, M. H. B. (2019). Building children's character: Ethnographic study of Maja Labo Dahu culture at Bima community. Jurnal Iqra': Kajian Ilmu Pendidikan, 4(2), 182-201. DOI: https://doi.org/10.25217/ji.v4i2.582.

Vitasurya, V. R. (2016). Local wisdom for sustainable development of rural tourism, case on Kaliburu and Lopati Village, Province of Daerah Istimewa Yogyakarta. Procedia-Social and behavioral sciences 216, 97-108. DOI: https:// doi.org/10.1016/j.sbspro.201 5.12.014.

Wagiran. (2012). Pengembangan karakter berbasis kearifan lokal Hamemayu Hayuning Bawana (identifikasi nilainilai karakter berbasis budaya). Jurnal Pendidikan Karakter, 2(2), 329-339. DOI: https://doi.org/10.21831/jpk.v 0i3.1249.
White, R. \& Warfa, N. (2011). Building schools of character: A Case-study investigation of character education's impact on school climate, pupil behavior and curriculum delivery. Journal of Applied Social Psychology 41(1), 45 - 60. DOI: 10.1111/j.15591816.2010.00701.x

Zuchdi, D. (2009). Humanisasi pendidikan: Menemukan kembali pendidikan yang manusiawi. Jakarta: Bumi Aksara.

Zuchdi, D., Prasetya, Z. K., \& Masruri. M. S. (2010). Pengembangan model pendidikan karakter terintegrasi dalam pembelajaran bidang studi di sekolah dasar. Cakrawala Pendidikan, 29(3), 112. DOI: https://doi.org/10.21831/cp.v1i3.224.

Zulfikar, E. (2019). Takut kepada allah dalam al-Qur'an: Analisis tafsir sufistik ayat-ayat khasyyatullah. Hermeneutik: Jurnal Ilmu Al Qur'an dan Tafsir, 13(1), 142-161. DOI:10.21043/hermeneutik.v13i1.5561. 